Journal of Zhejiang University-SCIENCE A (Applied Physics \& Engineering)

ISSN 1673-565X (Print); ISSN 1862-1775 (Online)

www.zju.edu.cn/jzus; www.springerlink.com

E-mail: jzus@zju.edu.cn

\title{
Predicting unstable toughness of concrete based on initial toughness criterion*
}

\author{
Long-bang QING ${ }^{\dagger 1,2}$, Wen-ling TIAN ${ }^{\dagger 1,2}$, Juan $\mathrm{WANG}^{3}$ \\ $\left({ }^{1}\right.$ College of Civil Engineering, Hebei University of Technology, Tianjin 300401, China) \\ $\left({ }^{2}\right.$ Civil Engineering Technology Research Center of Hebei Province, Tianjin 300401, China) \\ $\left({ }^{3}\right.$ College of Water Conservancy and Environment Engineering, Zhengzhou University, Zhengzhou 450001, China) \\ †E-mail: qlongbang@126.com; hebut_tm@163.com \\ Received Aug. 8, 2013; Revision accepted Nov. 5, 2013; Crosschecked Jan. 14, 2014
}

\begin{abstract}
The fracture processes of concrete were described by a cohesive crack model based on initial toughness criterion. The corresponding analytical method to predict the instability state was proposed. In this model, the initial toughness was adopted as the crack propagation criterion and the weight function method was used to calculate the stress intensity factor and the crack opening displacement caused by the cohesive stress. The unstable toughness can be easily obtained using the proposed method without measuring parameters at the critical state that was necessary in traditional methods. The proposed method was verified by existing experimental data of wedge splitting specimens with different grades of concrete and the sensitivity of the results on the tensile softening curve was discussed. The results demonstrate that the proposed method can well predict the peak load, the critical effective crack length, and the unstable toughness of concrete specimens. Moreover, the calculated unstable toughness is not sensitive to the tensile softening curve.
\end{abstract}

Key words: Concrete, Fracture, Initial toughness, Unstable toughness, Wedge splitting tests

doi:10.1631/jzus.A1300261 Document code: A CLC number: TU528.1

\section{Introduction}

A large number of experimental studies on concrete fracture have shown that an obvious fracture process zone (FPZ) exists at the crack tip (Bazant and Planas, 1998). The traditional linear elastic fracture mechanics (LEFM), is no longer applicable to the analysis of the concrete fracture process (Jenq and Shah, 1985a) when the size of FPZ is comparable to the structure. To date, numerous nonlinear models for

\footnotetext{
Corresponding author

* Project supported by the National Natural Science Foundation of China (Nos. 51309073 and 51309203), the Specialized Research Fund for the Doctoral Program of Higher Education (No. 20131317120012), and the Open Research Fund Program of State Key Laboratory of Hydroscience and Engineering (No. sklhse-2014-C-02), China

(C) Zhejiang University and Springer-Verlag Berlin Heidelberg 2014
}

concrete fracture have been developed from different perspectives and based on various assumptions. The primary models and their characteristics are briefly summarized herein.

The fictitious crack model (FCM) (Hillerborg et al., 1976) and crack band model (CBM) (Bazant and Oh, 1983) both considering the softening relation in the FPZ, were primarily solved numerically. The size effect law (SEL) developed by Bazant (1984) analyzes the size effect of the fracture by comparing nominal stress in the failure of structures with different sizes. The effective crack model (ECM) (Karihaloo and Nallathambi, 1990), known as the equivalent LEFM, has an explicit analytical solution. The two-parameter fracture model (TPFM) proposed by Jenq and Shah (1985a) was based on the assumption that crack propagation starts when the stress intensity factor and crack tip opening displacement (CTOD) 
reach their critical values. The critical stress intensity factor $K_{\mathrm{IC}}^{\mathrm{S}}$ in both ECM and TPFM was calculated from the peak load $P_{\max }$ and critical effective crack length $a_{\mathrm{c}}$ using a formula developed in LEFM.

Three different stages in the concrete fracture processes have been identified, namely, crack initiation, stable crack propagation, and unstable crack propagation (Xu and Reinhardt, 1999a). To depict the three stages of crack propagation without compromising simplicity, Xu and Reinhardt (1999a) developed the double- $K$ model, which employed the initial toughness $K_{\mathrm{IC}}^{\mathrm{ini}}$ and the unstable toughness $K_{\mathrm{IC}}^{\mathrm{un}}$ as control parameters of the two important instantaneous states of crack initiation and instability, respectively. Macroscopic damage in concrete is believed to be initiated once the stress intensity factor at the crack tip reaches $K_{\mathrm{IC}}^{\text {ini }}$ (Zhang and Xu, 2011). Crack instability is the catastrophic point between the stable and unstable crack propagation stages and is significant in investigating the mechanisms of concrete fracture. The double- $K$ model has been playing an important role in engineering practice. For instance, $K_{\mathrm{IC}}^{\mathrm{ini}}$ and $K_{\mathrm{IC}}^{\text {un }}$ have been used in safety warning systems (DL/T $5332-2005,2006)$ and in evaluating the performance of concrete structures with cracks.

The initial toughness $K_{\mathrm{IC}}^{\mathrm{ini}}$ can be easily obtained using formulae of the initial cracking load and initial crack length based on LEFM (Xu and Reinhardt, 1999a). Several measurement methods for the initial cracking load, such as tests using photo-elastic coating, laser speckle (Xu and Reinhardt, 1999a) and strain gauge (Zhang and $\mathrm{Xu}, 2011$ ), and analytical methods have been formulated. $\mathrm{Xu}$ and Reinhardt (1999b; 1999c; 2000) proposed the double-K method and developed a simplified method later. Kumar and Barai (2009) developed a weight function method. The comparison of the above analytical methods can be found in (Zhang and $\mathrm{Xu}, 2011)$. Recently, Qing and $\mathrm{Li}$ (2013) proposed a theoretical method to obtain $K_{\mathrm{IC}}^{\mathrm{ini}}$ based on experimental peak load. Alternatively, as an easy method, Reinhardt and Xu (1999) and Zhang et al. (2010) determined the initial cracking load by the transition point that separates the linear and nonlinear segments of the load $P$-CMOD (crack mouth opening displacement) curve.
Nevertheless, predicting the unstable toughness $K_{\mathrm{IC}}^{\text {un }}$ is difficult without making any assumption. In the experimental aspect, $K_{\mathrm{IC}}^{\mathrm{un}}$ can be calculated by the peak load $P_{\max }$ and the critical effective crack length $a_{\mathrm{c}}$, which were mainly measured at the peak load state through the three point bending (TPB) specimens or wedge splitting (WS) specimens (DL/T 5332-2005, 2006). However, the critical effective crack length $a_{\mathrm{c}}$ was usually difficult to measure accurately. In traditional methods, $a_{\mathrm{c}}$ was calculated by critical crack mouth opening displacement $\mathrm{CMOD}_{\mathrm{c}}$ through empirical formulae (Xu and Reinhardt, 1999b; 1999c; Kumar and Barai, 2009; Zhang and Xu, 2011). Furthermore, in the numerical aspect, a similar step-by-step procedure must be followed until the maximum load was reached (Wu et al. 2007; Dong et al., 2013). Therefore, it is of significance to establish a simple theoretical method for predicting the unstable toughness $K_{\mathrm{IC}}^{\mathrm{un}}$.

Based on the analysis of concrete fracture mechanisms, the current study attempts to develop an easy-to-use theoretical method for predicting the unstable toughness $K_{\mathrm{IC}}^{\mathrm{un}}$. In this method, the initial toughness $K_{\mathrm{IC}}^{\mathrm{ini}}$ was adopted as the control parameter of crack propagation and a weight function method was used to calculate the stress intensity factor and the crack opening displacement caused by the cohesive stress. Then the proposed method was verified using experimental data on wedge splitting specimens. The sensitivity of the results to the tensile softening curve was discussed.

\section{Model development}

\subsection{Fracture processes of concrete}

As mentioned in the previous section, the fracture processes in concrete structures include three different stages: crack initiation, stable crack propagation, and unstable fracture. To identify the three different states, the cohesive crack model with crack tip singularity (Elices and Planas, 1991) was adopted in the present work. Fig. 1 shows the different characteristics of the three stages, including the initial crack length $a_{0}$, crack propagation length $\Delta a$, external 


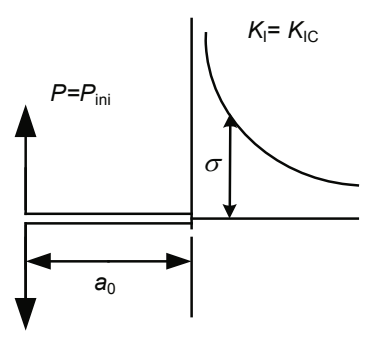

(a)

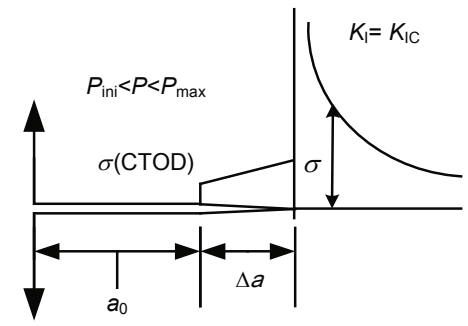

(b)

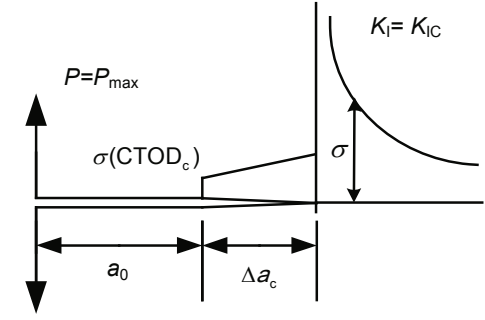

(c)

Fig. 1 Three stages of the concrete fracture processes

(a) Crack initiation; (b) Stable crack growth; (c) Unstable fracture

load $P$, stress strength factor $K_{\mathrm{I}}$, and fracture toughness $K_{\mathrm{IC}}$. Take type I load for example. When concrete is subjected to monotonic loading, cracks will not propagate until the external load $P$ reaches the crack initiation load $P_{\text {ini }}\left(P=P_{\text {ini }}\right)$, and $K_{\mathrm{I}}=K_{\mathrm{IC}}^{\text {ini }}$ (Fig. 1a). After crack initiation and as the external load $P$ continuously increases, the crack starts to propagate, and a cohesive zone forms ahead of the initial crack, as shown in Fig. 1b. This period is commonly known as the stable crack propagation stage. Then the external load $P$ reaches the peak (critical) value $P_{\max }$ (Fig. 1c). After that, unstable crack propagation may occur and the external load $P$ decreases.

A typical $P-a / D$ ( $a$ is the effective crack length, and $D$ is the specimen height) curve is shown in Fig. 2 (Reinhardt and Xu, 1999; Kumar and Barai, 2008; Qing and $\mathrm{Li}, 2013)$. When $P$ reaches the initial cracking load $P_{\text {ini, }}$, crack begins to grow and it gradually and nonlinearly increases with $a$. When $P$ reaches the peak load $P_{\max }, a=a_{\mathrm{c}}$. Then $P$ gradually decreases with $a$. The derivation of $P$ to $a$ at $P=P_{\max }$ can be assumed to be continuous (Qing and Li, 2013). The maximum theory can also be adopted to predict the crack instability.

\subsection{Criterion for concrete fracture}

As discussed above, a crack is initiated in concrete once the external load reaches the crack load $P_{\text {ini }}$ or the stress intensity factor increases to the initial toughness $K_{\mathrm{IC}}^{\mathrm{ini}}$. Thus, $K_{\mathrm{IC}}^{\mathrm{ini}}$ can be regarded as the toughness of the structural material to crack growth attributable to external forces. In the present study, the following criterion for crack initiation and propagation was employed (Xu and Reinhardt, 1999a; Wu

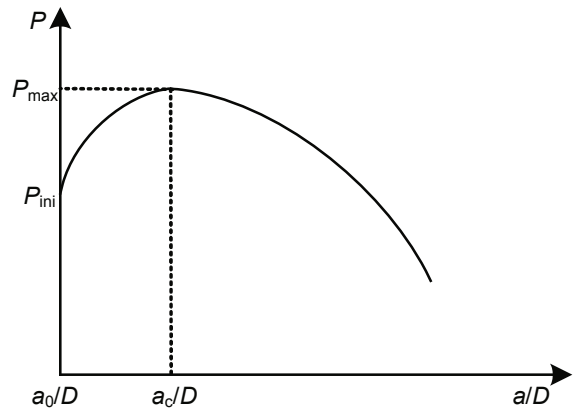

Fig. 2 A typical $P$ - $a / D$ curve of concrete fracture (Qing and $\mathrm{Li}, 2013$ )

et al., 2007; Dong et al., 2013):

$$
K_{\mathrm{I}}=K_{\mathrm{IC}}^{\mathrm{ini}}
$$

where $K_{\mathrm{I}}$ is the stress intensity factor at the tip of the effective crack tip in a mode I fracture.

Before crack initiation, LEFM can be applied, and $K_{\mathrm{I}}$ can be calculated by

$$
K_{\mathrm{I}}=K_{\mathrm{I}}^{\mathrm{P}}
$$

where $K_{\mathrm{I}}^{\mathrm{P}}$ is the stress intensity factor attributable to the external load in a mode I fracture.

After the crack initiation, $K_{\mathrm{I}}$ can be expressed by the superposition scheme:

$$
K_{\mathrm{I}}=K_{\mathrm{I}}^{\mathrm{P}}+K_{\mathrm{I}}^{\mathrm{C}},
$$

where $K_{\mathrm{I}}^{\mathrm{C}}$ is the stress intensity factor attributable to cohesive stress. 


\subsection{Cohesive stress distribution}

It is assumed that the cohesive stress distribution on the FPZ can be expressed by Eq. (3) (Li et al., 2012). The cohesive stress at the tip of the effective crack equals the tensile strength. The cohesive stress at the tip of the initial crack and the crack tip opening displacement CTOD satisfy the tensile softening curve.

$$
\sigma(b)=\sigma_{\mathrm{s}}+\left(f_{\mathrm{t}}-\sigma_{\mathrm{s}}\right)\left(\frac{x-a_{0}}{a-a_{0}}\right)^{m}
$$

where $\sigma_{\mathrm{s}}$ is the stress on the initial crack tip, $f_{\mathrm{t}}$ is the tensile strength, and $m$ is the cohesion distribution index.

According to Eq. (3), the distribution of cohesive stress changes with the index $m$. When $m=1$, the cohesive stress distribution is linear. Eq. (3) is similar to the cohesive force distribution adopted by Reinhardt (1985). The difference is that the cohesive stress at the initial crack tip is not zero in the present model. Based on the theoretical model, the corresponding analytical approach is developed in the following section.

\section{Analytical method for fracture}

Take the WS specimen for example, the configuration of the WS specimen is shown in Fig. 3 (DL/T 5332-2005, 2006).

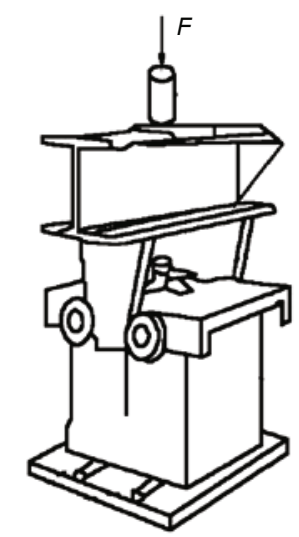

Fig. 3 Test set-up of WS specimen (DL/T 5332-2005, 2006) 1999c):

$$
K_{\mathrm{I}}^{\mathrm{P}}=\frac{P}{B \sqrt{D}} k(\alpha),
$$

where $\alpha=a / D$, and $k(\alpha)$ is a geometric factor, which can be calculated by (DL/T 5332-2005, 2006):

$$
k(\alpha)=\frac{3.675[1-0.12(\alpha-0.45)]}{(1-\alpha)^{3 / 2}} .
$$

Eq. (5) is valid for $0.2 \leq \alpha \leq 0.8$ with $2 \%$ accuracy (Xu and Reinhardt, 1999c).

To obtain the value of $K_{\mathrm{I}}^{\mathrm{C}}$, a distribution of cohesive stress is assumed on the fictitious crack in an infinite strip (Jenq and Shah, 1985b). Previous studies have shown that the descending segment of the $P$-CMOD curve is affected by the cohesive stress distribution, while the peak load and critical crack mouth opening displacement are almost not affected (Li et al., 2012). Therefore, to simplify the analysis of the fracture processes, a linear cohesive stress assumption ( $m=1)$ was adopted for the propagation state of concrete cracks in the current study. The cohesive stress distribution is shown in Fig. 4, where $\sigma_{\mathrm{s}}$ (CTOD) is the function of CTOD.

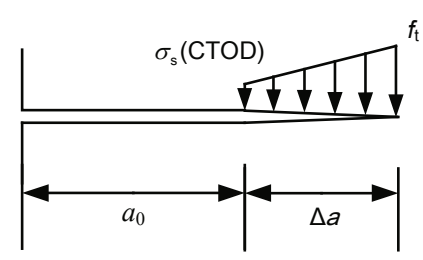

Fig. 4 Linear distribution of cohesive stress

The weight function method proposed by Kumar and Barai (2009) was adopted in this study to calculate $K_{\mathrm{I}}^{\mathrm{C}}$ :

$$
K_{\mathrm{I}}^{\mathrm{C}}=\frac{2}{\sqrt{2 \pi a}} g(a)
$$

where $g(a)$ can be expressed using the following fourth-order weight function:

$$
g(a)=A_{1} a\left(2 s^{1 / 2}+M_{1} s+\frac{2}{3} M_{2} s^{3 / 2}+\frac{M_{3}}{2} s^{2}\right)
$$




$$
\begin{aligned}
& +A_{2} a^{2}\left[\frac{4}{3} s^{3 / 2}+\frac{M_{1}}{2} s^{2}+\frac{4}{15} M_{2} s^{5 / 2}\right. \\
& \left.+\frac{M_{3}}{6}\left(1-\left(\frac{a_{0}}{a}\right)^{3}-3 s \frac{a_{0}}{a}\right)\right],
\end{aligned}
$$

where $A_{1}=\sigma_{\mathrm{s}}(\mathrm{CTOD}), A_{2}=\left[f_{\mathrm{t}}-\sigma(\mathrm{CTOD})\right] /\left(a-a_{0}\right), s=$ $1-a_{0} / a, M_{1}, M_{2}$, and $M_{3}$ can be expressed by $\alpha$ (Kumar and Barai, 2009).

The CTOD and $\sigma_{\mathrm{s}}(\mathrm{CTOD})$ values are required to calculate $K_{\mathrm{I}}^{\mathrm{C}}$ using Eqs. (6) and (7), where $\sigma_{\mathrm{s}}(\mathrm{CTOD})$ can be expressed by (Reinhardt et al., 1986):

$$
\begin{aligned}
\sigma_{\mathrm{s}}(\mathrm{CTOD})= & f_{\mathrm{t}}\left\{\left[1+\left(\frac{c_{1} \mathrm{CTOD}}{w_{0}}\right)^{3}\right] \exp \left(\frac{-c_{2} \mathrm{CTOD}}{w_{0}}\right)\right. \\
& \left.-\frac{\mathrm{CTOD}}{w_{0}}\left(1+c_{1}^{3}\right) \exp \left(-c_{2}\right)\right\},
\end{aligned}
$$

where $c_{1}, c_{2}$, and $w_{0}$ are parameters.

CTOD in Eq. (8) needs to be calculated by adding up two displacements caused by the external load $P$ and cohesive stress. Using Paris' displacement formula (Tada et al., 2000; Mai, 2002), CTOD can be expressed by

$$
\begin{aligned}
\text { CTOD }= & \frac{2}{E} \int_{a_{0}}^{a} \frac{P}{B \sqrt{D}} k\left(\frac{\xi}{D}\right) m\left(a_{0}, \xi\right) \mathrm{d} \xi \\
& -\frac{2}{E} \int_{a_{0}}^{a} \frac{2}{\sqrt{2 \pi \xi}} g(\xi) m(\xi, a) \mathrm{d} \xi
\end{aligned}
$$

where $E$ is the elasticity modules, $\xi$ is the integration variable, $m(x, a)$ can be expressed using the following fourth-order weight function (Kumar and Barai, 2009):

$$
\begin{aligned}
m(x, a)= & \frac{2}{\sqrt{2 \pi(a-x)}}\left[1+M_{1}\left(1-\frac{x}{a}\right)^{1 / 2}\right. \\
& \left.+M_{2}\left(1-\frac{x}{a}\right)+M_{3}\left(1-\frac{x}{a}\right)^{3 / 2}\right] .
\end{aligned}
$$

Thus, using Eqs. (7)-(9), $g(a)$ can be derived, and $K_{\mathrm{I}}^{\mathrm{C}}$ can be obtained using Eq. (6). Then, substi- tuting Eq. (4) for $K_{\mathrm{I}}^{\mathrm{P}}$ and Eq. (6) for $K_{\mathrm{I}}^{\mathrm{C}}$ into Eq. (2b) leads to:

$$
P=\zeta(a)+\eta(a) K_{\mathrm{IC}}^{\mathrm{ini}},
$$

where

$$
\begin{aligned}
& \zeta(a)=\frac{2 B \sqrt{D}}{\sqrt{2 \pi a} k(\alpha)} g(a), \\
& \eta(a)=B \sqrt{D} \frac{1}{k(\alpha)} .
\end{aligned}
$$

Eq. (11) obviously shows that the external load $P$ can be explicitly expressed as a function of the effective crack length $a$. The derivation of this equation with respect to $a$ at the moment of the crack instability can be expressed by the following partial differential equation:

$$
\left.\frac{\partial P}{\partial a}\right|_{a=a_{\mathrm{c}}}=0,
$$

and $\frac{\partial P}{\partial a}$ is calculated by

$$
\frac{\partial P}{\partial a}=\zeta^{\prime}(a)+\eta^{\prime}(a) K_{\mathrm{IC}}^{\mathrm{ini}},
$$

where

$$
\begin{gathered}
\zeta^{\prime}(a)=\frac{2 B \sqrt{D}}{\sqrt{2 \pi}} \frac{g^{\prime}(a) k(\alpha) \sqrt{a}-g(a)\left[k^{\prime}(a) \sqrt{a}+\frac{k(\alpha)}{2 \sqrt{a}}\right]}{k^{2}(\alpha) a}, \\
\eta^{\prime}(a)=-B \sqrt{D} \frac{k^{\prime}(\alpha)}{k^{2}(\alpha)} .
\end{gathered}
$$

$g^{\prime}(a)$ can be expressed as

$$
\begin{aligned}
g^{\prime}(a)= & \left(A_{1}+A_{1}^{\prime} a\right)\left(2 s^{1 / 2}+M_{1} s+\frac{2}{3} M_{2} s^{3 / 2}+\frac{M_{3}}{2} s^{2}\right) \\
& +A_{1} a\left(s^{-1 / 2}+M_{1}+M_{2} s^{1 / 2}+M_{3} s\right) s^{\prime} \\
& +A_{2} a^{2}\left[\left(2 s^{1 / 2}+M_{1} s+\frac{2}{3} M_{2} s^{3 / 2}\right) s^{\prime}\right. \\
& \left.+\frac{M_{3}}{2}\left(\frac{a_{0}^{3}}{a^{4}}-s^{\prime} \frac{a_{0}}{a}+s \frac{a_{0}}{a^{2}}\right)\right]
\end{aligned}
$$




$$
\begin{aligned}
& +\left(2 A_{2} a+A_{2}^{\prime} a^{2}\right)\left[\frac{4}{3} s^{3 / 2}+\frac{M_{1}}{2} s^{2}\right. \\
& \left.+\frac{4}{15} M_{2} s^{5 / 2}+\frac{M_{3}}{6}\left(1-\left(\frac{a_{0}}{a}\right)^{3}-3 s \frac{a_{0}}{a}\right)\right],
\end{aligned}
$$

where

$$
\begin{aligned}
& s^{\prime}=\frac{a_{0}}{a^{2}}, \\
& A_{1}^{\prime}=\frac{\partial \sigma_{\mathrm{s}}(\mathrm{CTOD})}{\partial a}=\frac{\partial \sigma_{\mathrm{s}}(\mathrm{CTOD})}{\partial \mathrm{CTOD}} \frac{\partial \mathrm{CTOD}}{\partial a}, \\
& A_{2}^{\prime}=\frac{-\sigma_{\mathrm{s}}^{\prime}(\mathrm{CTOD})\left(a-a_{0}\right)-\left[f_{\mathrm{t}}-\sigma_{\mathrm{s}}(\mathrm{CTOD})\right]}{\left(a-a_{0}\right)^{2}} .
\end{aligned}
$$

$k^{\prime}(\alpha)$ can be expressed as

$$
\begin{aligned}
& k^{\prime}(\alpha) \\
& =\frac{-0.441(1-\alpha)^{3 / 2}+(5.810175-0.6615 \alpha)(1-\alpha)^{1 / 2}}{(1-\alpha)^{3}} .
\end{aligned}
$$

If the initial toughness $K_{\mathrm{IC}}^{\mathrm{ini}}$ is given, the critical effective crack length $a_{\mathrm{c}}$ can be calculated using Eq. (12) by iterating method. Then, the critical crack tip opening displacement $\mathrm{CTOD}_{\mathrm{c}}$ and the peak load $P_{\max }$ can be obtained by substituting $a=a_{\mathrm{c}}$ into Eq. (9) and Eq. (11), respectively. The unstable toughness $K_{\mathrm{IC}}^{\mathrm{un}}$ can be calculated by substituting $a=a_{\mathrm{c}}$ and $P=$
$P_{\max }$ into Eq. (4). Hence, an analytical approach for calculating $K_{\mathrm{IC}}^{\text {un }}$ was developed.

\section{Results and discussion}

\subsection{Verification of the analytical method}

In this section, the proposed method for concrete fracture was verified using the data from $\mathrm{Xu}$ et al. (2006)'s experiments on WS specimens with different maximum aggregate sizes. The parameters of the specimens are shown in Table 1. In the experiments, the crack initiation load $P_{\text {ini }}$ was measured by resistance strain gauges and the initial toughness $K_{\mathrm{IC}}^{\mathrm{ini}}$ was obtained by the LEFM formula.

According to the experimental conditions, the parameters in Eq. (8) for the proposed method were taken as follows: $c_{1}=3, c_{2}=6.93$, and $w_{0}=160 \mu \mathrm{m}$ (Reinhardt et al., 1986).

The calculated and measured values of the peak load $P_{\max }$ are compared in Tables $2-4$. It can be seen from the comparison that the values of the peak load $P_{\max }$ calculated by the proposed method are generally in good agreement with the experimental values for different maximum aggregate sizes of concrete specimens. It can be concluded that the method is effective for predicting the instability of concrete.

Moreover, the values of unstable toughness $K_{\mathrm{IC}}^{\text {un }}$

Table 1 Parameters of the wedge splitting specimens

\begin{tabular}{ccccccc}
\hline $\begin{array}{c}\text { Specimen } \\
\text { No. }\end{array}$ & $\begin{array}{c}\text { Specimen size, } \\
2 H \times D \times B(\mathrm{~mm})\end{array}$ & $\begin{array}{c}\text { Maximum aggre- } \\
\text { gate size }(\mathrm{mm})\end{array}$ & $\begin{array}{c}a_{0} \\
(\mathrm{~mm})\end{array}$ & $\begin{array}{c}E \\
(\mathrm{GPa})\end{array}$ & $\begin{array}{c}\text { Compressive strength, } \\
f_{\mathrm{c}}(\mathrm{MPa})\end{array}$ & $\begin{array}{c}\text { Tensile strength, } \\
f_{\mathrm{t}}(\mathrm{MPa})\end{array}$ \\
\hline WS13 & $300 \times 300 \times 200$ & 20 & 150 & 33.4 & 34.2 & 2.76 \\
WS14 & $600 \times 600 \times 200$ & 20 & 300 & 33.4 & 34.2 & 2.76 \\
WS15 & $800 \times 800 \times 200$ & 20 & 400 & 33.4 & 34.2 & 2.76 \\
WS16 & $1000 \times 1000 \times 200$ & 20 & 500 & 33.4 & 34.2 & 2.76 \\
WS17 & $1200 \times 1200 \times 200$ & 20 & 600 & 33.4 & 34.2 & 2.76 \\
WS32 & $300 \times 300 \times 200$ & 40 & 150 & 29.1 & 34.3 & 3.04 \\
WS22 & $600 \times 600 \times 200$ & 40 & 300 & 29.1 & 34.3 & 3.04 \\
WS34 & $800 \times 800 \times 200$ & 40 & 400 & 29.1 & 34.3 & 3.04 \\
WS35 & $1000 \times 1000 \times 200$ & 40 & 500 & 29.1 & 34.3 & 3.04 \\
WS23 & $600 \times 600 \times 250$ & 80 & 300 & 29.1 & 34.3 & 3.04 \\
WS24 & $800 \times 800 \times 250$ & 80 & 400 & 29.1 & 34.3 & 3.04 \\
WS25 & $1000 \times 1000 \times 250$ & 80 & 500 & 29.1 & 34.3 & 3.04 \\
WS26 & $1200 \times 1200 \times 250$ & 80 & 600 & 29.1 & 34.3 & 3.04 \\
\hline
\end{tabular}


Table 2 Comparison of the predicted and measured results (maximum aggregate size: $20 \mathrm{~mm}$ )

\begin{tabular}{cccccccccc}
\hline $\begin{array}{c}\text { Specimen } \\
\text { No. }\end{array}$ & $\begin{array}{c}\text { Specimen size, } \\
2 H \times D \times B(\mathrm{~mm})\end{array}$ & $\begin{array}{c}a_{0} \\
(\mathrm{~mm})\end{array}$ & $\begin{array}{c}P_{\text {ini }} \\
(\mathrm{kN})\end{array}$ & $\begin{array}{c}\text { Predicted } \\
a_{\mathrm{c}} / D\end{array}$ & $\begin{array}{c}\text { Predicted } \\
P_{\max }(\mathrm{kN})\end{array}$ & $\begin{array}{c}\text { Experimental } \\
P_{\max }(\mathrm{kN})\end{array}$ & $\begin{array}{c}\text { Predicted } \\
K_{\mathrm{IC}}^{\text {un }}(1)\end{array}$ & $\begin{array}{c}\text { Experimental } \\
K_{\mathrm{IC}}^{\text {un }}(2)\end{array}$ & $(1) /(2)$ \\
\hline WS13-1 & $300 \times 300 \times 200$ & 150 & 7.181 & 0.620 & 11.668 & 12.173 & 1.637 & 1.690 & 0.969 \\
WS13-2 & $300 \times 300 \times 200$ & 150 & 10.916 & 0.567 & 14.156 & 12.801 & 1.642 & 1.958 & 0.838 \\
WS13-4 & $300 \times 300 \times 200$ & 150 & 7.909 & 0.607 & 12.095 & 11.492 & 1.614 & 1.759 & 0.918 \\
Mean & & & 8.669 & 0.598 & 12.639 & 12.155 & 1.631 & 1.802 & 0.908 \\
\hline WS14-1 & $600 \times 600 \times 200$ & 300 & 19.308 & 0.569 & 25.387 & 25.550 & 2.098 & 2.224 & 0.943 \\
WS14-2 & $600 \times 600 \times 200$ & 300 & 18.484 & 0.583 & 24.787 & 22.667 & 2.148 & 2.462 & 0.872 \\
WS14-4 & $600 \times 600 \times 200$ & 300 & 18.000 & 0.583 & 24.437 & 23.408 & 2.117 & 2.004 & 1.057 \\
Mean & & & 18.597 & 0.578 & 24.870 & 23.875 & 2.121 & 2.230 & 0.957 \\
\hline WS15-1 & $800 \times 800 \times 200$ & 400 & 23.788 & 0.597 & 32.848 & 30.758 & 2.596 & 2.191 & 1.185 \\
WS15-2 & $800 \times 800 \times 200$ & 400 & 24.546 & 0.584 & 33.387 & 31.136 & 2.511 & 2.135 & 1.176 \\
WS15-3 & $800 \times 800 \times 200$ & 400 & 17.403 & 0.639 & 28.776 & 29.351 & 2.667 & 2.102 & 1.269 \\
Mean & & & 21.912 & 0.607 & 31.670 & 30.415 & 2.591 & 2.143 & 1.210 \\
\hline WS16-1 & $1000 \times 1000 \times 200$ & 500 & 32.495 & 0.570 & 42.677 & 42.137 & 2.741 & 2.974 & 0.922 \\
WS16-2 & $1000 \times 1000 \times 200$ & 500 & 30.478 & 0.584 & 41.205 & 39.000 & 2.777 & 2.851 & 0.974 \\
WS16-3 & $1000 \times 1000 \times 200$ & 500 & 24.235 & 0.612 & 36.929 & 31.494 & 2.753 & 2.250 & 1.224 \\
Mean & & & 29.069 & 0.589 & 40.270 & 37.544 & 2.757 & 2.692 & 1.040 \\
\hline WS17-1 & $1200 \times 1200 \times 200$ & 600 & 33.368 & 0.584 & 46.734 & 46.326 & 2.878 & 3.231 & 0.891 \\
WS17-2 & $1200 \times 1200 \times 200$ & 600 & 36.699 & 0.584 & 49.142 & 55.183 & 3.026 & 3.028 & 0.999 \\
WS17-3 & $1200 \times 1200 \times 200$ & 600 & 40.045 & 0.570 & 51.689 & 50.355 & 3.033 & 3.112 & 0.975 \\
Mean & & & 36.704 & 0.579 & 49.188 & 50.621 & 2.979 & 3.124 & 0.955 \\
\hline
\end{tabular}

Table 3 Comparison of the predicted and measured results (maximum aggregate size: $\mathbf{4 0} \mathbf{m m}$ )

\begin{tabular}{cccccccccc}
\hline Specimen & Specimen size, & $a_{0}$ & $P_{\text {ini }}$ & Predicted & Predicted & Experimental & Predicted & Experimental & \multirow{2}{*}{$(1) /(2)$} \\
No. & $2 H \times D \times B(\mathrm{~mm})$ & $(\mathrm{mm})$ & $(\mathrm{kN})$ & $a_{\mathrm{c}} / D$ & $P_{\max }(\mathrm{kN})$ & $P_{\max }(\mathrm{kN})$ & $K_{\mathrm{IC}}^{\text {un }}(1)$ & $K_{\mathrm{IC}}^{\text {un }}(2)$ & 1.021 \\
\hline WS32-1 & $300 \times 300 \times 200$ & 150 & 8.234 & 0.593 & 12.237 & 11.221 & 1.556 & 1.524 & 1.121 \\
WS32-2 & $300 \times 300 \times 200$ & 150 & 8.848 & 0.580 & 11.384 & 9.433 & 1.381 & 1.232 & 1.127 \\
WS32-3 & $300 \times 300 \times 200$ & 150 & 8.431 & 0.593 & 12.366 & 10.727 & 1.572 & 1.371 & 1.147 \\
Mean & & & 8.504 & 0.589 & 11.996 & 10.460 & 1.503 & 1.376 & 1.096 \\
\hline WS33-2 & $600 \times 600 \times 200$ & 300 & 18.973 & 0.569 & 25.017 & 24.511 & 2.068 & 1.957 & 1.057 \\
WS33-3 & $600 \times 600 \times 200$ & 300 & 18.588 & 0.569 & 24.725 & 21.956 & 2.044 & 2.132 & 0.959 \\
WS33-4 & $600 \times 600 \times 200$ & 300 & 16.091 & 0.583 & 22.912 & 21.242 & 1.985 & 2.006 & 0.990 \\
Mean & & & 17.884 & 0.574 & 24.218 & 22.570 & 2.032 & 2.032 & 1.002 \\
\hline WS34-1 & $800 \times 800 \times 200$ & 400 & 22.306 & 0.584 & 30.683 & 27.349 & 2.308 & 2.016 & 1.145 \\
WS34-2 & $800 \times 800 \times 200$ & 400 & 18.766 & 0.597 & 28.215 & 27.049 & 2.230 & 2.106 & 1.059 \\
WS34-4 & $800 \times 800 \times 200$ & 400 & 26.711 & 0.570 & 34.006 & 32.000 & 2.439 & 2.713 & 0.899 \\
Mean & & & 22.594 & 0.584 & 30.968 & 28.799 & 2.326 & 2.278 & 1.034 \\
\hline WS35-2 & $1000 \times 1000 \times 200$ & 500 & 21.337 & 0.598 & 33.364 & 29.866 & 2.363 & 2.071 & 1.141 \\
WS35-3 & $1000 \times 1000 \times 200$ & 500 & 19.284 & 0.612 & 32.076 & 25.634 & 2.391 & 1.884 & 1.269 \\
WS35-4 & $1000 \times 1000 \times 200$ & 500 & 21.837 & 0.598 & 33.698 & 32.700 & 2.386 & 2.336 & 1.021 \\
Mean & & & 20.819 & 0.603 & 33.046 & 29.400 & 2.380 & 2.097 & 1.144 \\
\hline
\end{tabular}


Table 4 Comparison of the predicted and measured results (maximum aggregate size: $80 \mathbf{~ m m}$ )

\begin{tabular}{cccccccccc}
\hline $\begin{array}{c}\text { Specimen } \\
\text { No. }\end{array}$ & $\begin{array}{c}\text { Specimen size, } \\
2 H \times D \times B(\mathrm{~mm})\end{array}$ & $\begin{array}{c}a_{0} \\
(\mathrm{~mm})\end{array}$ & $\begin{array}{c}P_{\text {ini }} \\
(\mathrm{kN})\end{array}$ & $\begin{array}{c}\text { Predicted } \\
a_{\mathrm{c}} / D\end{array}$ & $\begin{array}{c}\text { Predicted } \\
P_{\max }(\mathrm{kN})\end{array}$ & $\begin{array}{c}\text { Experimental } \\
P_{\max }(\mathrm{kN})\end{array}$ & $\begin{array}{c}\text { Predicted } \\
\text { un }\end{array}(1)$ & $K_{\mathrm{IC}}^{\text {un }}(2)$ & $(1) /(2)$ \\
\hline WS23-2 & $600 \times 600 \times 250$ & 300 & 16.525 & 0.638 & 27.138 & 23.407 & 2.312 & 2.465 & 0.938 \\
WS23-4 & $600 \times 600 \times 250$ & 300 & 17.451 & 0.624 & 27.675 & 24.340 & 2.233 & 2.260 & 0.988 \\
Mean & & & 16.988 & 0.631 & 27.407 & 23.874 & 2.273 & 2.363 & 0.963 \\
\hline WS24-1 & $800 \times 800 \times 250$ & 400 & 29.425 & 0.584 & 40.357 & 36.833 & 2.429 & 2.867 & 0.847 \\
WS24-3 & $800 \times 800 \times 250$ & 400 & 31.575 & 0.584 & 41.924 & 35.859 & 2.523 & 2.385 & 1.058 \\
WS24-4 & $800 \times 800 \times 250$ & 400 & 19.594 & 0.639 & 34.058 & 32.178 & 2.525 & 2.766 & 0.913 \\
Mean & & & 26.865 & 0.602 & 38.780 & 34.957 & 2.492 & 2.673 & 0.939 \\
\hline WS25-1 & $1000 \times 1000 \times 250$ & 500 & 25.000 & 0.626 & 42.102 & 43.711 & 2.649 & 2.814 & 0.941 \\
WS25-2 & $1000 \times 1000 \times 250$ & 500 & 34.093 & 0.584 & 48.006 & 45.163 & 2.588 & 3.043 & 0.850 \\
WS25-4 & $1000 \times 1000 \times 250$ & 500 & 20.590 & 0.640 & 39.637 & 39.194 & 2.636 & 2.308 & 1.142 \\
Mean & & & 26.561 & 0.617 & 43.248 & 42.689 & 2.624 & 2.722 & 0.978 \\
\hline WS26-1 & $1200 \times 1200 \times 250$ & 600 & 45.168 & 0.570 & 60.206 & 54.000 & 2.826 & 2.931 & 0.964 \\
WS26-2 & $1200 \times 1200 \times 250$ & 600 & 37.663 & 0.598 & 54.773 & 47.340 & 2.836 & 3.326 & 0.853 \\
Mean & & & 41.416 & 0.584 & 57.490 & 50.670 & 2.831 & 3.129 & 0.909 \\
\hline
\end{tabular}

are also shown in Tables 2-4. The calculated values of $K_{\mathrm{IC}}^{\mathrm{un}}$ by the proposed method generally agree well with those by experimental method. Some of the calculated results are slightly different from those obtained by the experimental method, for example, the ratio of the predicted result to experimental result of WS15 is 1.21. According to Eq. (4), the discrepancy in the unstable toughness results from the critical relative effective crack length $a_{\mathrm{c}} / D$. The primary reason is that, as mentioned above, an empirical formula was adopted in the experimental method to calculate the critical effective length $a_{\mathrm{c}}$. The proposed method, differing from the experimental method, is capable of considering the effects of both external load and cohesive force when calculating $a_{\mathrm{c}}$.

\subsection{Effect of tensile softening curve}

To study the sensitivity of the method to the shape of the tensile softening curve, two groups of parameters characterizing different tensile softening curves were used to predict fracture using the proposed theoretical method.

The parameters of first group were $c_{1}=3, c_{2}=6.93$, and $w_{0}=160 \mu \mathrm{m}$, which were adopted in the last section. For comparison, the second set of the softening curve parameters was taken as as $c_{1}=1.5, c_{2}=6.3$, and $w_{0}=90 \mu \mathrm{m}$. The tensile softening curves represented by these two sets of parameters are shown in Fig. 5 .

With these different parameters, the values of
$P_{\max }, a_{\mathrm{c}} / D$, and $K_{\mathrm{IC}}^{\mathrm{un}}$ were calculated using the proposed method, and the results are shown in Figs. 6-8. As can be seen from Figs. 6-8, the calculated $P_{\max }$, $a_{\mathrm{c}} / D$, and $K_{\mathrm{IC}}^{\text {un }}$ using the first group of parameters are slightly different from those of the other one. Generally, this disparity in the calculated results using these two sets of parameters is considered to be insignificant in view of the great difference between the two tensile softening curves. For example, the fracture energy $G_{\mathrm{F}}$ (area under the tensile softening curve) corresponding to the first softening curve is about twice that for the second one.

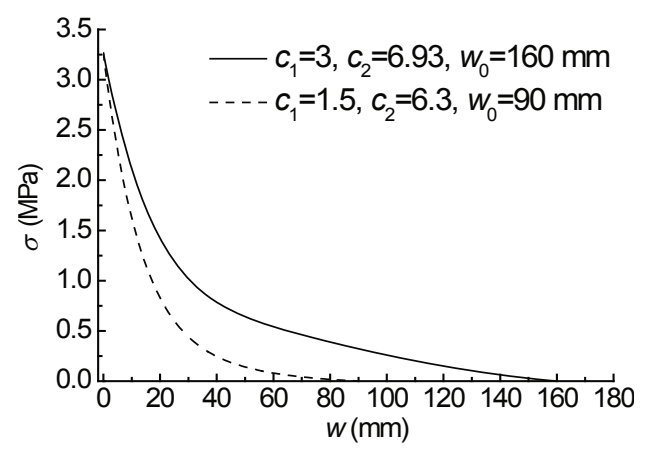

Fig. 5 Tensile softening curves

\section{Conclusions}

In this study, the instability state of fracture in concrete was predicted by a theoretical model which 
adopted the initial toughness $K_{\mathrm{IC}}^{\mathrm{ini}}$ as the crack propagation criterion, and used the weight function method to calculate the stress intensity factor and the crack opening displacement caused by the cohesive stress. The applicability of the proposed method was verified by experimental data obtained on WS specimens, and the parameters at the peak load state, such as the peak load $P_{\max }$, critical effective crack length $a_{\mathrm{c}}$ and unstable toughness $K_{\mathrm{IC}}^{\text {un }}$, were calculated using the proposed method. The good agreement between

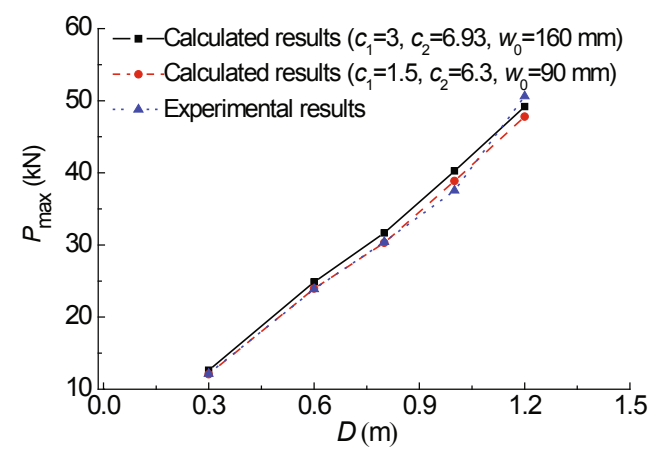

(a)

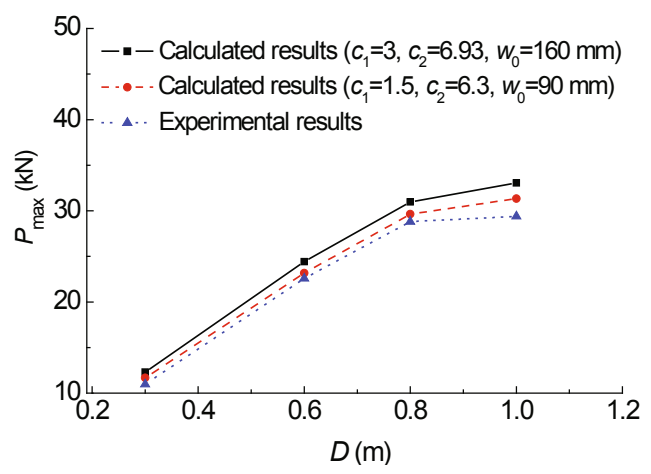

(b)

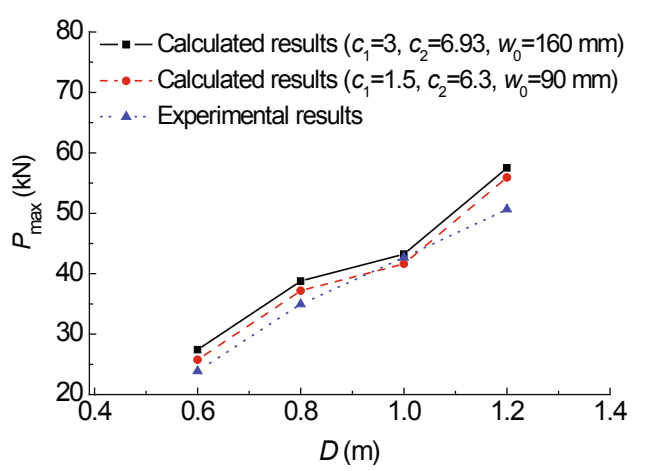

(c)

Fig. 6 Average values of $\boldsymbol{P}_{\max }$ for specimens with different maximum aggregate sizes of $20 \mathrm{~mm}$ (a), $40 \mathrm{~mm}$ (b), and $80 \mathrm{~mm}(\mathrm{c})$ the calculated results and the experimental results demonstrates that the proposed method can accurately predict the unstable toughness $K_{\mathrm{IC}}^{\text {un }}$. In addition, the sensitivity of the results to the tensile softening curve was discussed. The results showed that the proposed method for fracture is not sensitive to the tensile softening curve, which verifies the reasonability of the proposed method. Future studies can be conducted from many aspects, such as the investigation of measurement methods for the effective crack length $a_{\mathrm{c}}$.

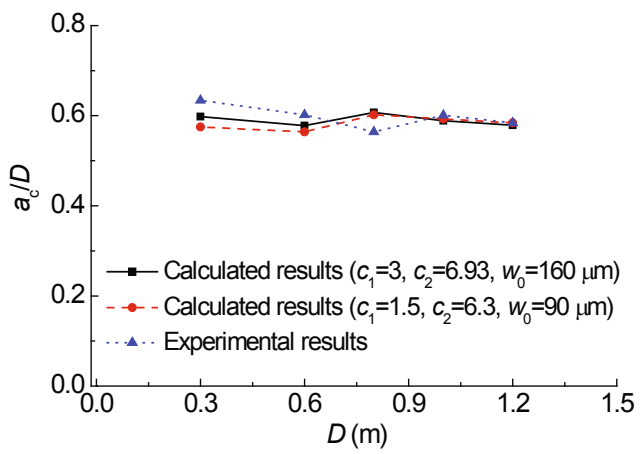

(a)

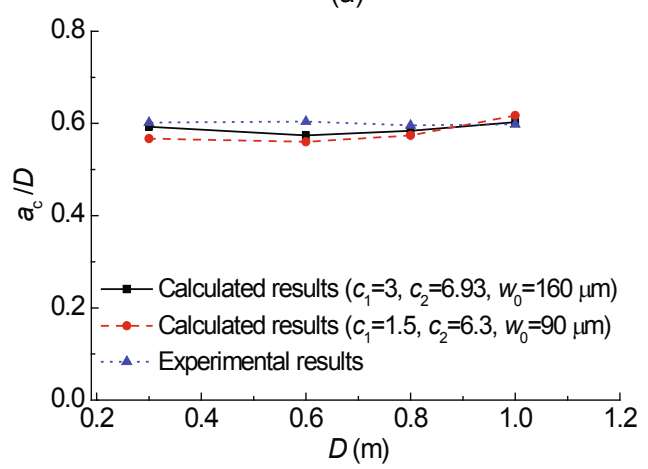

(b)

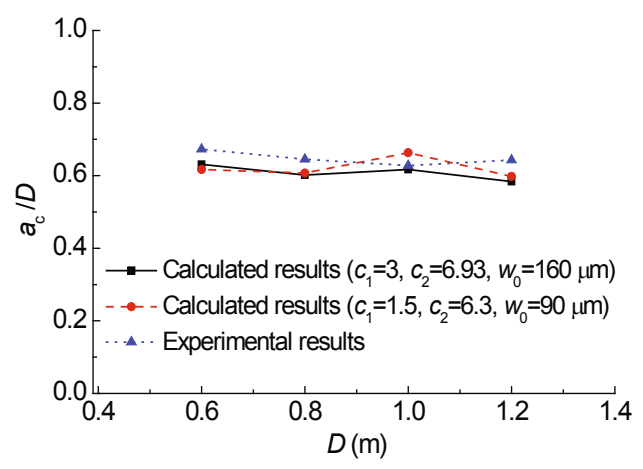

(c)

Fig. 7 Average values of $a_{\mathrm{c}} / D$ for specimens with different maximum aggregate sizes of $20 \mathrm{~mm}$ (a), $40 \mathrm{~mm}$ (b), and $80 \mathrm{~mm}(\mathrm{c})$ 


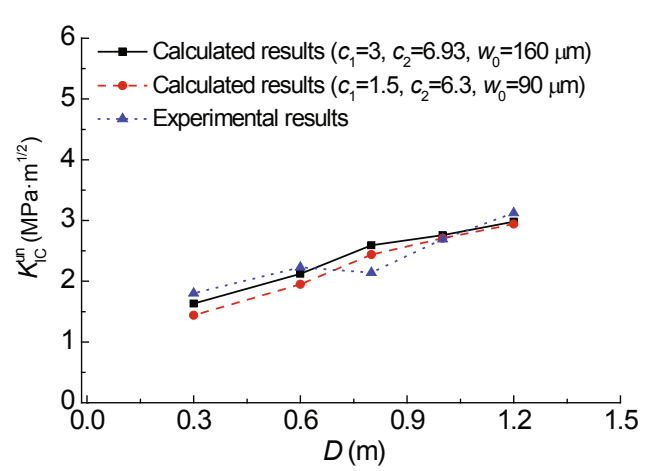

(a)

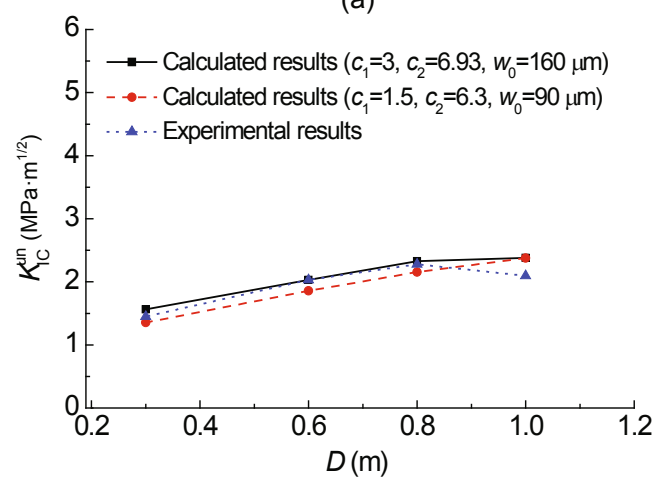

(b)

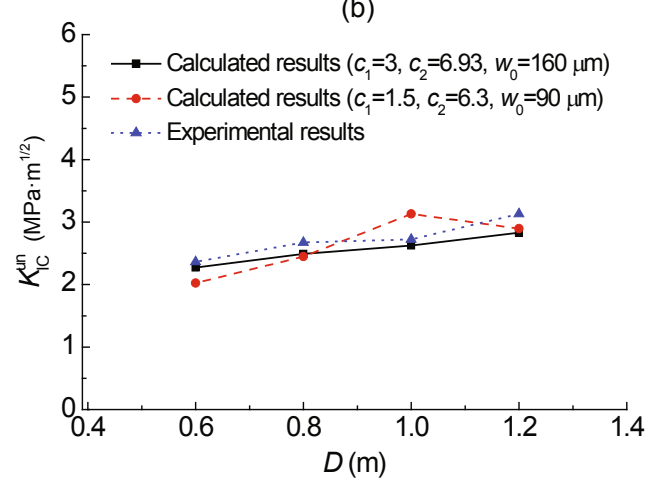

(c)

Fig. 8 Average values of $K_{\mathrm{IC}}^{\mathrm{un}}$ for specimens with different maximum aggregate sizes of $20 \mathrm{~mm}$ (a), $40 \mathrm{~mm}$ (b), and 80 $\mathbf{m m}(\mathbf{c})$

\section{References}

Bazant, Z.P., 1984. Size effect in blunt fracture: concrete, rock, metal. Journal of Engineering Mechanics, 110(4):518535. [doi:10.1061/(ASCE)0733-9399(1984)110:4(518)]

Bazant, Z.P., Oh, B.H., 1983. Crack band theory for fracture of concrete. Material and Structure, 16(3):155-177. [doi:10. 1007/BF02486267]

Bazant, Z.P., Planas, J., 1998. Fracture and Size Effect in Concrete and Other Quasibrittle Materials. CRC Press, Boca Raton.

DL/T 5332-2005, 2006. Specification for Fracture Test of Hydraulic Concrete. China Electric Power Press, Beijing, China (in Chinese).
Dong, W., Wu, Z.M., Zhou, X.M., 2013. Calculating crack extension resistance of concrete based on a new crack propagation criterion. Construction and Building Materials, 38:879-889. [doi:10.1016/j.conbuildmat.2012.09.037]

Elices, M., Planas, J., 1991. Material models. In: Elfgren, L. (Ed.), Fracture Mechanics of Concrete Structures from Theory to Applications. Report of RILEM Technical Committee 90-FMT. Chapman \& Hall, London, p.16-65.

Hillerborg, A., Modeer, M., Petersson, P.E., 1976. Analysis of crack formation crack growth in concrete by means of fracture mechanics and finite elements. Cement and Concrete Research, 6(6):773-782. [doi:10.1016/0008-8846 (76)90007-7]

Jenq, Y.S., Shah, S.P., 1985a. Two parameter fracture model for concrete. Journal of Engineering Mechanics, 111(10): 1227-1241. [doi:10.1061/(ASCE)0733-9399(1985)111: 10(1227)]

Jenq, Y.S., Shah, S.P., 1985b. A fracture toughness criterion for concrete. Engineering Fracture Mechanics, 21(5):10551069. [doi:10.1016/0013-7944(85)90009-8]

Karihaloo, B.L., Nallathambi, P., 1990. Effective cracks model for the determination of fracture toughness (KICS) of concrete. Engineering Fracture Mechanics, 35(4-5):637645. [doi:10.1016/0013-7944(90)90146-8]

Kumar, S., Barai, S.V., 2008. Influence of specimen geometry and size-effect on the $K_{R}$-curve based on the cohesive stress in concrete. International Journal of Fracture, 152(2):127-148. [doi:10.1007/s10704-008-9275-6]

Kumar, S., Barai, S.V., 2009. Determining double- $K$ fracture parameters of concrete for compact tension and wedge splitting tests using weight function. Engineering Fracture Mechanics, 76(7):935-948. [doi:10.1016/j.engfracmech. 2008.12.018]

Li, Q.B., Qing, L.B., Guan, J.F., 2012. Analysis of the whole fracture process of concrete considering effects of cohesive distribution. Journal of Hydraulic Engineering, 43(Sup.):31-36 (in Chinese).

Mai, Y.W., 2002. Cohesive zone and crack-resistance $(R)$-curve of cementitious materials and their fibre-reinforced composites. Engineering Fracture Mechanics, 69(2):219-234. [doi:10.1016/S0013-7944(01)00086-8]

Qing, L.B., Li, Q.B., 2013. A theoretical method for determining initiation toughness based on experimental peak load. Engineering Fracture Mechanics, 99:295-305. [doi:10.1016/j.engfracmech.2013.01.012]

Reinhardt, H.W., 1985. Plain concrete modeled as an elastic strain-softening material at fracture. Engineering Fracture Mechanics, 22(5):787-796. [doi:10.1016/0013-7944(85) 90108-0]

Reinhardt, H.W., Xu, S.L., 1999. Crack extension resistance based on the cohesive force in concrete. Engineering Fracture Mechanics, 64(5):563-587. [doi:10.1016/ S0013-7944(99)00080-6]

Reinhardt, H.W., Cornelissen, H.A.W., Hordijk, D.A., 1986. Tensile tests and failure analysis of concrete. Journal of Structural Engineering, 112(11):2462-2477. [doi:10. 1061/(ASCE)0733-9445(1986)112:11(2462)] 
Tada, H., Paris, P.C., Irwin, G., 2000. The Stress Analysis of Cracks Handbook, Third Edition. New York.

Wu, Z.M., Dong, W., Liu, K., Yang, S.T., 2007. Mode I crack propagation criterion of concrete and numerical simulation on complete process of cracking. Journal of Hydraulic Engineering, 38:46-52 (in Chinese).

Xu, S.L., Reinhardt, H.W., 1999a. Determination of double-K criterion for crack propagation in quasi-brittle fracture, Part I: experimental investigation of crack propagation. International Journal of Fracture, 98(2):111-149. [doi:10. 1023/A:1018668929989]

Xu, S.L., Reinhardt, H.W., 1999b. Determination of double- $K$ criterion for crack propagation in quasi-brittle fracture, Part II: analytical evaluating and practical measuring methods for three-point bending notched beams. International Journal of Fracture, 98(2):151-177. [doi:10.1023/ A:1018740728458]

Xu, S.L., Reinhardt, H.W., 1999c. Determination of double- $K$ criterion for crack propagation in quasi-brittle fracture, Part III: compact tension specimens and wedge splitting specimens. International Journal of Fracture, 98(2): 179-193. [doi:10.1023/A:1018788611620]

Xu, S.L., Reinhardt, H.W., 2000. A simplified method for determining double-K fracture parameters for three-point bending tests. International Journal of Fracture, 104(2): 181-209. [doi:10.1023/A:1007676716549]

Xu, S.L., Zhou, H.G., Gao, H.B., Zhao, S.Y., 2006. An experimental study on double-K fracture parameters of concrete for dam construction with various grading aggregates. China Civil Engineering Journal, 39(11):50-62.

Zhang, J., Leung, K.Y., Xu, S.L., 2010. Evaluation of fracture parameters of concrete from bending test using inverse analysis approach. Materials and Structure, 43(6):857875. [doi:10.1617/s11527-009-9552-5]

Zhang, X.F., Xu, S.L., 2011. A comparative study on five approaches to evaluate double-K fracture toughness parameters of concrete and size effect analysis. Engineering Fracture Mechanics, 78(10):2115-2138. [doi:10.1016/j. engfracmech.2011.03.014]

\section{中文概要：}

本文题目 : 基于起裂㓞度准则的混凝土失稳㓞度预测研究

Predicting unstable toughness of concrete based on initial toughness criterion

研究目的：研究混凝土失稳韧度的理论预测方法。

创新要点: 1. 提出混凝土失稳韧度的理论预测方法; 2. 利用楔入䢃拉试件计算不同级配混凝土的失稳韧

度; 3. 研究失稳㓞度受拉伸软化曲线的影响。

研究方法：1. 基于起裂韧度扩展准则, 采用理论分析手段研究混凝土的失稳韧度计算方法; 2. 利用楔入 䢃拉试件 (见图3) 计算不同级配混凝土的失稳㓞度。

重要结论：1. 基于起裂韧度准则可合理地预测峰值荷载状态及失稳韧度; 2 . 混凝土失稳韧度受断裂能的 影响较小; 3 . 拉伸软化曲线对混凝土失稳韧度的影响较小。

关键词组 : 混凝土: 起裂韧度: 失稳韧度: 楔入䢃拉实验 